\title{
The Relationship of Medication Adherence and Social Functioning of Persons with Schizophrenia in the Long-term Period
}

\author{
Jenny Marlindawani Purba*, Roymond H. Simamora, Evi Karota \\ Department of Community and Psychiatry Nursing, Faculty of Nursing, Universitas Sumatera Utara, Medan, Indonesia
}

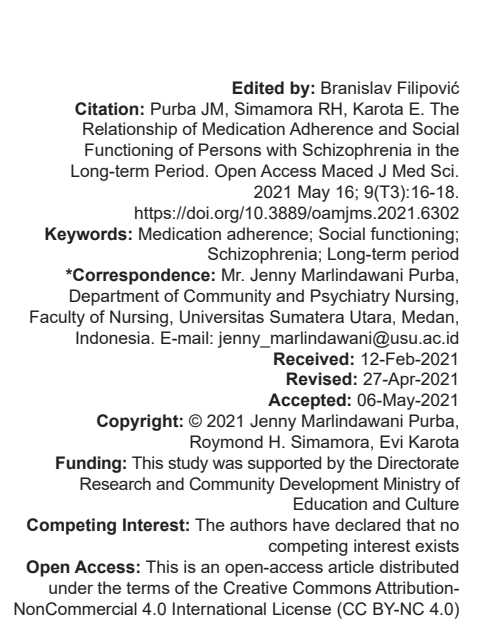

Abstract

BACKGROUND: Medication adherence is an essential aspect of the daily lives of persons with schizophrenia, while in-compliance is related to their social functioning performance.

AIM: The study aims to analyze the prolonged relationship between medication adherence and the social functioning of persons with chronic schizophrenia.

METHODS: A descriptive correlation method was carried out on 60 persons with schizophrenia at Pasung in North Sumatra Province, Indonesia, using questionnaires.

RESULTS: The results indicate that $68.3-51.7 \%$ of respondents had low adherence to medication and socia functioning, respectively. Spearman rank claimed that there is a strong relationship between medication adherence and social functioning among chronic schizophrenia persons. Furthermore, the result reported that medication adherence positively affected social functioning among persons with schizophrenia.

CONCLUSIONS: Medication adherence is a priority for maintaining the behavior of people living with schizophrenia to help them control their psychotic symptoms. Therefore, it can enhance their social functioning performance and daily living activity. Family participation is needed for continuous medication program and relapse rate prevention.

\section{Introduction}

Schizophrenia is a chronic mental disorder that causes individuals to experience difficulty processing information and making interpersonal relationships with others [1]. Furthermore, people suffering from schizophrenia are prone to relapse. There is a yearly increase in the prevalence of schizophrenia worldwide, especially in Indonesia. According to the Basic Health Research [2], the prevalence of schizophrenia showed a significant increase in the number of cases in North Sumatra Province from 0.09\% in 2013 to $0.6 \%$ in 2018. This led to an increase in the amount of medications consumed and periodic visits to hospitals [3]. There are two types of antipsychotics, namely, typical and atypical. The typical types are first-generation antipsychotics, such as haloperidol and fluphenazine, while atypical are second-generation, such as risperidone and olanzapine [4].

Medication adherence plays an essential role in successful long-term therapy for chronic diseases [5]. Adherence is defined as patients' ability to take drugs (interval and dose) according to the doctor's prescriptions [6]. Patients' non-compliance when taking medication is usually due to a lack of knowledge on the associated adverse effects, low insight, and not knowing the benefits of taking medication [7].
Non-adherence to taking medication is one of the causes of recurrence in schizophrenics. This occurs because patients forget to take their medication, feel bored, or worse after taking it, with fear of drug dependence and feeling sluggish when walking [8]. A study carried out by Purba et al. [9], showed that the patients fail to comply with taking medication after leaving the hospital due to laziness and tiredness. The family can take the role of medication supervisor for their loved ones. The success of the treatment program would improve the poor cognitive function of schizophrenia. Good cognitive function can scale up social function so that they can carry out daily activities without depending on the family [10].

\section{Methods}

\section{Population and sample}

This is a descriptive correlation study, with data obtained from patients' homes in Community Health Center North Sumatra Province, Indonesia. The inclusion criteria of the samples were patients with the following characteristics: (1) 18-65 years old, (2) diagnosed with schizophrenia, (3) have been to Pasung, (4) clinically 
stable (BPRS <36), (5) able to communicate verbally, and (6) willing to participate in the study. The consecutive sampling method was used to select data from 60 respondents based on the inclusion criteria. Instruments of the study consist of the medication adherence rating scale (MARS) and the functioning assessment short test (FAST). Furthermore, the questionnaire consists of 10 statements with the option of yes and no answers given scores of 1 and 0 , respectively. Meanwhile, the FAST is self-reported to measure the social functioning of schizophrenia and consists of 24 items. The internal consistency reliability of the MARS and FAST was 0.98 and 0.83 .

\section{Statistical analysis}

Data were analyzed using a computerized system with $p<0.05$. Univariate analysis was carried out to determine respondents' frequency distribution and percentage characteristics, their medication adherence, and social functioning. The Spearman rank correlation test was used to analyze the relationship between medication adherence and social functioning among persons with schizophrenia.

\section{Ethical approval}

This study was approved by the Research Ethics Commission of the University of North Sumatra, number 395/KEP/USU/2020. Informed consent was given to all respondents, with their confidentiality maintained.

\section{Results}

\section{Characteristics of respondents}

Table 1 shows that the majority of the respondents were in the age range of 36-45 years, more than $50 \%$ are women, with an average educational background of high school. Furthermore, over $50 \%$ of the respondents received BPJS non-PBI from the government, with an average illness length of $1-5$ years, and $56.7 \%$ getting atypical antipsychotics drugs.

Table 2 shows that $68.3 \%$ of the respondents have low medication adherence. In addition, more than $50 \%$ perform low social functioning.

Table 3 shows the positive relationship between medication adherence and social functioning of persons with schizophrenia $(r=0.83 ; p=0.001)$.

\section{Discussion}

The result of the study showed a relationship between medication adherence and social functioning.
Table 1: Distribution frequency and percentage of characteristics respondents $(n=60)$

\begin{tabular}{lll}
\hline Characteristics & $\mathrm{f}$ & $\%$ \\
\hline Age (years) & 6 & \\
17-25 & 14 & 10.0 \\
$26-35$ & 16 & 23.3 \\
$36-45$ & 12 & 26.7 \\
$46-55$ & 12 & 20.0 \\
$56-65$ & & 20.0 \\
Gender & 28 & 46.7 \\
Male & 32 & 56.3 \\
Female & 3 & \\
Job & 8 & 5.0 \\
Government employee & 17 & 13.3 \\
Public employee & 12 & 28.3 \\
Small traders & & 53.3 \\
Not working & 31 & 51.7 \\
Health insurance & 26 & 43.3 \\
BPJS non-PBI & 3 & 5.0 \\
BPJS PBI & & \\
Private & 35 & 58.3 \\
Duration of illness (years) & 12 & 43.3 \\
1-5 & 13 & 5.0 \\
6-9 & & \\
10-13 & 26 & 43.3 \\
Medication & 34 & 56.7 \\
$\quad$ Antipsychotic typical & & \\
Antipsychotic atypical & &
\end{tabular}

A recent study indicates that compliance with medication tends to have better social functioning among people with schizophrenia. Patients with high drug adherence can perform better, interact with others, and actively carry out social activities [10].

Table 2: Distribution and percentage of attitude and medication adherence $(n=60)$

\begin{tabular}{lll}
\hline Variable 1 & $\mathrm{f}$ & $\%$ \\
\hline Medication adherence & & \\
High & 10 & 16.7 \\
Moderate & 9 & 15.0 \\
Low & 41 & 68.3 \\
Social functioning & & \\
$\quad$ High & 12 & 20.0 \\
Moderate & 17 & 28.3 \\
Low & 31 & 51.7 \\
\hline
\end{tabular}

On the other hand, those not complying with the drug have a negative impact on social functioning [11]. The low adherence to taking this medication is due to the respondent's ignorance and inability to take the drugs as prescribed. They also do not know the benefits of drugs taken with weak documentation. Most of the respondents in this study did not have the desire to take medication due to the drug's side effects.

Table 3: Relationship between medication adherence and social functioning $(n=60)$

\begin{tabular}{llll}
\hline Variable 1 & Variable 2 & $\mathrm{r}$ & $\mathrm{p}$ \\
\hline Medication adherence & Social functioning & 0.83 & 0.001 \\
\hline
\end{tabular}

They also reported that there was no difference between taking and not taking medication. Most of the respondents stated that they felt uncomfortable taking medicine, and they also reported changes in their bodies, such as sluggish body movements and drowsiness, which make it difficult for them to concentrate on carrying out daily activities. Respondents also stated that they often forget to take their medication, stop the drug in the presence of symptoms, and are bored in taking the medication for a prolonged period. A negative response to medication can affect non-adherence [12], and this condition leads to recurrence [13]. Relapse is common in patients that discontinue with the oral antipsychotics medication [14]. 
This study also showed that $51.7 \%$ of the respondents' social function was in low category. Some were unable to perform self-care, lacked concentration, weak in numeracy, and had difficulty managing money. The presence of schizophrenic patients in families often creates conflict. They also have difficulty initiating interactions with other people and are always reminded to carry out their daily activities at home, such as washing dishes and cleaning [15]. This study also shows that such patients cannot defend their rights and find it difficult to secure jobs, thereby increasing the family burden [16]. More than half of the respondents with schizophrenia used in this study were without jobs. Therefore, their ability to adhere to doctors' prescriptions can help them achieve optimal social functioning with their loved ones. In addition, the role of the family as a supervisor of taking medication is needed to enhance adherence to taking medication and social function.

\section{Conclusions}

Medication adherence and social functioning are essential aspects for people suffering from schizophrenia. Compliance with medication tends to enable better social functioning and their ability to perform their daily activities effectively. The use of long-acting injectable antipsychotic is recommended to reduce non-compliance medication.

\section{Acknowledgment}

The authors are grateful to the respondents and caregivers that willingly participated in this research. The authors are also grateful to the Directorate Research and Community Development Ministry of Education and Culture (Number 11/AMD?E1/KP.PTNBH/2020) for their support.

\section{References}

1. Stuart GW, Laraia MT. Principles and Practice of Psychiatric Nursing. St. Louis: Mosby; 2013.

2. NIHRD (National Institute of Health Research and Development) Ministry of Health of Republic of Indonesia. Basic Health Research Report; 2018. Available from: https://www.kesmas. kemkes.go.id/assets/upload/dir_519d41d8cd98f00/files/Hasilriskesdas-2018_1274.pdf. [Last accessed on 2020 Aug 12]

3. Yulianti MD, Cahaya N, Srikartika VM. Antipsychotics use and side effects in patients with schizophrenia at Sambang Lihum Hospital South Kalimantan, Indonesia. J Sains Farm Klin.
2017;3(2):153-64. https://doi.org/10.29208/jsfk.2017.3.2.108

4. Hu Y, Young AJ, Ehli EA, Nowotny D, Davies PS, Droke EA, et al. Metformin and berberine prevent olanzapine-induced weight gain in rats. PLoS One. 2014;9:e93310.

PMid:24667776

5. Lachaine J, Yen L, Beauchemin C, Hidgkins P. Medication adherence and persistence in the treatment of Canadian ulcerative colitis patients: Analyses with the RAMQ database. BMC Gastroenterol. 2013;13:23. https://doi. org/10.1186/1471-230x-13-23 PMid:23363459

6. Zeber JE, Manias E, Williams AF, Hutchins D, Udezi WA Roberts CS, et al. Medication adherence: A report of the ISPOR medication adherence and persistence special interest group. Value Health. 2013;16(5):891-90. https://doi.org/10.1016/j. jval.2013.04.014

PMid:23947984

7. Purba J, Suttharangsee W, Chaowalit A. Effectiveness of a coaching program for family caregivers of persons with schizophrenia: A randomized controlled trial. Walailak J Sci Tech 2017;14(1):11-24.

8. Settem VVJ, Karanadi H, Praharaj SK. Cognitive deficits, depressive symptoms, insight, and medication adherence in remitted patients with schizophrenia. Indian J Psychiatry. 2019;61(4):335-41. https://doi.org/10.4103/psychiatry. indianjpsychiatry_17_19

PMid:31391635

9. Purba JM, Simamora RH, Karota E, Siregar CT. Family support for persons with schizophrenia after physical restraint and confinement. Enferm Clin. 2020;30(Suppl 3):53-6. https://doi. org/10.1016/j.enfcli.2019.12.026

10. Popp BS, Minodora M, Moraru MO. Treatment adherence and social functioning in patients diagnosed with schizophrenia and treated with antipsychotic depot medication. Clujul Med. 2014;87(2):109-12. https://doi.org/10.15386/cjmed-292 PMid:26528009

11. Ozkan B, Erdem E, Ozsoy SD, Zararsiz G. The effects of psychoeducation and telepsychiatric follow-up on social functioning and medication adherence in the patients with schizophrenia. Anadolu Psikiyatr Derg. 2013;14(3):192-9. https://doi.org/10.5455/apd.35951

12. Xiao J, Mi W, Li L, Shi Y, Zhang H. High relapse rate and poor medication adherence in the Chinese population with schizophrenia: Results from an observational survey in the People's Republic of China. Neuropsychiatr Dis Treat. 2015;11:1161-7. https://doi.org/10.2147/ndt.s72367 PMid:26056450

13. Dushad R, Mintu M, Samaksha PB, Basavana GH. A study of drug attitude and medication adherence and its relationship with the impact of illness among the mentally ill. Arch Clin Psychiatry. 2019;46(4):85-8. https://doi. org/10.1590/0101-60830000000201

14. Kaplan G, Casov J, Zummo J. Impact of long-acting injectable antipsychotics on medication adherence and clinical functional, and economic outcomes of schizophrenia. Patient Prefer Adherence. 2013;7:1171-80. https://doi.org/10.2147/ppa.s53795 PMid:24265549

15. Duțescu MM, Popescu RE, Balcu L, Duica LC, Strunoiu LM, Alexandru DO, et al. Social functioning in schizophrenia clinical correlations. Curr Health Sci J. 2018;44(2):151-6. PMid:30746163

16. Lasebikan VO, Ayinde OO. Effects of psychopathology, functioning and antipsychotic medication adherence on caregivers' burden in schizophrenia. Indian J Psychol Med. 2013;35(2):135-40. https://doi.org/10.4103/0253-7176.116237 PMid:24049223 